
Acta Poetica 30-2

OTOÑO

2009

\title{
Comunidad literaria y deconstrucción. Entre el fin del relato y la archi-escritura: Blanchot, Kofman, Derrida
}

\author{
Joana Masó
}

El presente ensayo se propone relacionar tres figuras del texto literario después de la deconstrucción de la comunidad: el fin del relato literario en $L a$ folie du jour y "L'Idylle" de Maurice Blanchot, la palabra sofocada [La parole soffoquées] de Sarah Kofman y la archi-escritura en el pensamiento de Jacques Derrida. Abordaremos la escritura como un gesto filosófico con la finalidad de pensar la interrelación de lo literario y lo filosófico en estos autores franceses de la segunda mitad del siglo xx.

Palabras Clave: Blanchot, Kofman, Derrida.

The purpose of this essay is to relate three figures of the literary text after the deconstruction of the community: the end of the literary tale in Maurice Blanchot's La folie du jour and "L'Idylle", Sarah Kofman's suffocated word [La parole suffoquée] and the archi-writing in Derrida's thought. We will approach writing as a philosophical gesture in order to consider the intertwining of literature and philosophy in these three authors of the second half of the 20th century in France.

KEY WORDS: Blanchot, Kofman, Derrida.

Fecha de recepción: 13 de febrero de 2010

Fecha de aceptación: 3 de junio de 2010 

Joana Masó

Universidad de Barcelona

\section{Comunidad literaria y deconstrucción. Entre el fin del relato y la archi-escritura: Blanchot, Kofman, Derrida*}

Querría empezar mi reflexión sobre literatura y filosofía citando una frase de Maurice Blanchot en su artículo titulado "Las novelas de Sartre". Dice así: "la novela no tiene nada que temer de una tesis, a condición de que la tesis acepte no ser nada sin la novela. Porque la novela tiene su propia moral, que es la ambigüedad y el equívoco" (La parte del fuego, 203). Siguiendo la concepción blanchotiana de este tipo de "tesis" que no son nada "sin" las propias novelas o relatos de su autor, me concentraré en la delimitación de dichas "tesis" que podríamos llamar "literarias" y que se diferenciarían de las "tesis" tout court: a saber, "tesis" simplemente insertas dentro de lo que el propio Blanchot llama roman à thèse, novela de tesis, la cual "manifiesta aquello que significa y [...] se pone, honestamente, por entero, al servicio de su verdad: no está dividida contra sí misma, morirá”. Como colofón, en su descripción de esta

"El presente artículo ha sido realizado en el marco del proyecto de investigación "Representaciones de la comunidad en las escritoras y cineastas de la postmodernidad (Francia y países francófonos)", financiado por el Ministerio de Ciencia y Tecnología español fFI 2008 - 03621. 
novela monolítica y solidaria con las tesis que en ella están expuestas, Blanchot cita la famosa frase de Gide: "Con buenos sentimientos sólo se hace mala literatura" (190), en la que no podemos dejar de leer la siguiente crítica que Blanchot lanza a la novela de tesis: con buenas tesis sólo se hace mala literatura.

Se tratará, pues, de pensar la singularidad de lo que llamaremos tesis literarias, las cuales, sostiene Blanchot, no son ni idénticas ni semejantes a sí mismas, a su propio sentido, como ocurre con las tesis teóricas, puesto que la tesis literaria rompe toda posible identidad y abre en su seno el desdoblamiento de la palabra literaria. La duplicidad y ambigüedad de la tesis literaria se figura mediante la noche blanchotiana y se aleja así de la visibilidad diurna de la tesis teórica que, según Blanchot, dentro de la novela "está más visible que en su desnudez originaria, tan visible que ya no puede ofrecer ningún secreto" (188). Ciertamente, la tesis teórica dentro del texto literario está más visible y más expuesta que en su texto de origen. Y es precisamente este uso blanchotiano de la figuratividad - donde la palabra literaria ni es visible, ni se revela ni se desvela mediante figuras de la luz, donde la oscuridad se arranca a la luz (Blanchot, El espacio literario, 300) - el que nos permitirá pensar la crisis de la especulación que da lugar a una crisis de la palabra filosófica en tres autores franceses de la segunda mitad del siglo xx, Maurice Blanchot, Jacques Derrida y Sarah Kofman.

Sin duda, todos conocemos la célebre formulación blanchotiana "plus de récit après Auschwitz", "ya no más relato después de Auschwitz", que tanto el pensador de la deconstrucción, Jacques Derrida, como la filósofa Sarah Kofman han leído y comentado en algunos de sus libros. Sabemos, asimismo, que en esta frase lo que está en juego es una misma imposibilidad de cierta palabra literaria — "plus de récit", "ya no más relato"- y de cierto tipo de organización del sujeto en la comunidad después del exterminio de los judíos. El acontecimiento 
llamado Auschwitz imposibilitaría, entonces, simultáneamente, aquello que se ha venido entendiendo por "relato literario", así como la organización humana en una comunidad. Relato y comunidad llegarían, así pues, a su fin en ciertas filosofías de la deconstrucción.

Es quizás menos conocida la crítica que comparten Blanchot, Derrida y Kofman en relación con la noción de especulación. El fin de la especulación en la deconstrucción se inscribe en la crítica del concepto de inteligibilidad del sentido, propia de la palabra teórica y filosófica: Derrida critica la herencia indo-europea de la noción de saber, internamente relacionada con las filosofías del aparecer y de la luz; ${ }^{1}$ Blanchot problematiza el "privilegio desmesurado que se atribuye a la vista: privilegio que se presupone originalmente e implícitamente no sólo en toda metafísica, sino también en toda ontología (y, ni qué decir tiene, en toda fenomenología)" (La conversación infinita, 33); mientras que Kofman, en su libro Cámara oscura de la ideología, elabora un recorrido por el pensamiento de Marx, Nietzsche y Rousseau, para demostrar que toda ideología presupone un pensamiento especulativo.

Para Kofman, la especulación protege a la filosofía ante el horror, la muerte y la locura. La filosofía es profundamente especulativa porque funciona como un espejo -el speculum latino que dará la palabra especulación-, que se interpone entre la mirada de Medusa y la de Perseo, con la finalidad de evitar el cara a cara con la muerte y desviar, así, cualquier presencia

${ }^{1}$ Cfr., entre otros, Derrida, Mémoires d'aveugle. L'autoportrait et autres ruines, 18 , donde el filósofo denuncia que "ideîn, eîdos, idea: toda la historia, toda la semántica de la idea europea, en su genealogía griega, eso se sabe, se ve, asigna el ver al saber".

2 "Todas esas metáforas especulativas implican el mismo postulado: la existencia de un sentido originario, luz y sonido originarios que, de manera secundaria, vendrían a reflejarlos o a repercutirlos: lo 'real' y lo 'verdadero' preexistirían al conocimiento" (Kofman, 15-16). 
de lo mortificante y lo enloquecedor. La especulación es pues un gesto óptico que permite a la filosofía protegerse de aquello que le es radicalmente otro, inquietante, extraño, extranjero. Ésta es la lectura que Sarah Kofman desarrolla en su texto publicado póstumamente sobre el cuadro de Rembrandt, La lección de anatomía del Doctor Tulp, donde las miradas del conjunto de médicos forenses representados por Rembrandt ante un cuerpo muerto, desnudo y abierto, se desvían en su totalidad hacia el gran libro que se encuentra a los pies del cuerpo muerto como símbolo del saber. Kofman lee en el cuadro de Rembrandt la representación magistral de esta función especulativa del saber que refoule, rechaza, gracias al ejercicio del conocimiento, el cara a cara con la muerte: los médicos no miran el cadáver ni la cruda muerte que se expone ante ellos inevitablemente, sino que dirigen sus miradas hacia el saber del libro y de la tradición que los protege de la crudeza de la muerte. Es por ello que $L a$ lección de anatomía de Rembrandt, concluye Kofman, no supone "un triunfo de la muerte sino un triunfo sobre la muerte", por parte del saber (Kofman, "La mort conjurée", 43).

La crítica de la especulación es una de las claves para entender la lectura que hace Kofman de la palabra filosófica y de su régimen comunitario - en la medida en que ésta rechaza todo aquello que le es extranjero- en el relato de Maurice Blanchot "L'idylle", "El idilio". En Paroles suffoquées, libro donde Kofman relee El idilio de Blanchot y comenta su tan citada sentencia "ya no más relato después de Auschwitz", la filósofa francesa explicita el vínculo entre el fin de la palabra especulativa y cierto tipo de comunidad. Para Kofman, el relato de Blanchot pone en escena una comunidad idílica y profundamente especulativa que pretende "borra[r] toda huella de discordia, de diferencia, de muerte, que finge construirse sobre una armonía perfecta, una relación funcional que implica una unidad inmediata, y necesariamente una ficción de comunidad" que forzosamente necesita "enterrar con el Extranjero toda extranjeridad" 
(Paroles suffoquées, 22) para conservar su identidad — de idem, "lo mismo"-. Por ello, el protagonista de "El idilio" que entra en relación con la comunidad recibe el nombre de Alexandre, compuesto de la palabra griega anér, "hombre", y de los verbos aléxo, "apartar" y elaúno, "distanciar, echar", que designa etimológicamente y propiamente el hombre extranjero, el extranjero.

La comunidad idílica de Blanchot encuentra en la figura femenina de Louise su máxima expresión: una figura de la especulación pura. Louise o la comunidad quiere "captar en su espejo primaveral al extranjero" para robarle su alteridad, puesto que ella es la amante de "las imágenes y las bellas letras", escribe Kofman, la "niña de los ojos del librero"; Louise, "la luminosa, la ley apolínea" $(26,35,33)$; es la ley del día que encarna el espíritu comunitario y de identidad. Louise, lex o lux, la ley o la luz, dirá Kofman, es la figura blanchotiana que busca realizar el fin último de toda comunidad especulativa, a saber, el matrimonio del extranjero Alexandre con una mujer de la comunidad, con la finalidad de que "el extranjero muera en las primeras horas y sea un familiar el que, por la tarde, se instale en su lugar, del brazo de una chica sorprendida de acompañar a alguien que ya no le es desconocido" (Blanchot, "L'idylle", 47. La traducción es mía). ${ }^{3}$

Así pues, mediante la especulación de lo mismo, el idilio — del griego eidúllion, un pequeño eîdos, una pequeña "idea", "forma" o "imagen" - se constituye como una forma literaria que relata una historia nä̈ve y lírica: la de la armonía comunitaria que no se expone a la alteridad del extranjero. Aquí, el propio relato es la imagen, eîdos, o el espejo, speculum, de la identidad comunitaria, puesto que Blanchot subraya en él la resistencia a la otredad. “Cuándo podré irme del asilo?” pregunta Alexandre

${ }^{3}$ Cfr. también "El idilio", en Maurice Blanchot, 'Tiempo después', precedido por la 'Eterna reiteración'. 
al director de dicha institución, que le responde: "eso depende de usted. Cuando ya no tenga el sentimiento de ser un extranjero, entonces no habrá inconveniente en ver cómo se vuelve usted a convertir en extranjero" (32).

El relato se figurativiza, así pues, mediante la resistencia de la palabra especulativa ante su posibilidad de muerte, de horror o de locura, encarnados por la figura del otro. Por ello, en el pensamiento de Blanchot, el relato idílico se opone a toda escritura cuyo espectro sea Auschwitz, a toda escritura a-comunitaria y a-especulativa, puesto que Auschwitz, escribe Kofman, es "el nombre de aquello que no tiene ningún resultado ni ningún beneficio para lo especulativo". En efecto, si "ya no hay más relato después de Auschwitz" y si "cualquier relato será por ello anterior a Auschwitz sin tener en cuenta la fecha en la que ha sido escrito" (Paroles suffoquées, 13, 22), ello se debe a que el acontecimiento llamado Auschwitz rompe el horizonte de la especulación y, con él, el de la comunidad identitaria. Relato, palabra especulativa y comunidad datan de antes de Auschwitz, en la medida en que este acontecimiento abre irremediablemente a la exigencia de extranjeridad, de exilio y de afuera, para decirlo con Blanchot, experiencias de la alteridad que la especulación no hace más que rechazar.

Este relato blanchotiano que ya no puede tener lugar después de Auschwitz, después de la especulación y la experiencia de la identidad, se transformará en una escritura que discute el género "relato" y no hace sino exponer su ausencia. Sin embargo, tal y como hemos visto, la escritura de "El idilio", así como la de La locura de la luz de Blanchot, deshacen la posibilidad del relato problematizando las nociones de ley, luz, especulación y mismidad, así como también la irreductibilidad de la figura del extranjero. Ante la demanda de los médicos de La locura de la luz, que reclaman de su paciente y narrador un "relato verdadero del accidente que éste ha sufrido", la primera persona del texto no dudará en afirmar que "no era capaz de formar un 
relato con esos acontecimientos". Y ello porque los acontecimientos y los accidentes blanchotianos nunca forman relato en el sentido fuerte de la palabra, es decir: hilvanación de enunciación y sentido. Una prueba de ello es la célebre escritura en bucle de La locura de la luz, donde las frases que abren y cierran por citación interna este texto de 1973 y que constituyen la respuesta a la institución médica y jurídica, dicen así:

Me solicitaron: Cuéntenos cómo ha pasado todo exactamente — ¿Un relato? Comencé: Yo no soy sabio ni ignorante. He conocido alegrías. Decir esto es demasiado poco. Les conté la historia toda entera, que ellos escuchaban, me parece, con interés, al menos al principio. Sin embargo, el final fue para nosotros una común sorpresa. Después de este comienzo, decían, vaya a los hechos”. ¡Cómo es eso! El relato había terminado. Debí reconocer que no era capaz de formar un relato con estos acontecimientos $[\ldots]$ ¿Un relato? No, nada de relatos, nunca más (Blanchot, La locura de la luz, 62).

Ante el fin del relato y el idilio comunitario en Blanchot, Sarah Kofman recurre a la palabra "inspiración autobiográfica" que leemos en su libro Paroles suffoquées de 1987 y en el último libro publicado en su vida, Calle Ordener, Calle Labat, en 1994. Ambos libros se escriben como un testimonio de la persecución de los judíos que Kofman vivió en su propia piel por ser hija de un rabino francés de origen polaco que murió en Auschwitz en 1942. Asimismo, ambos mantienen un diálogo con el libro La especie humana de Robert Antelme, superviviente de Auschwitz, y con la escritura del desastre de Blanchot. Ante el fin del relato blanchotiano, empero, Kofman propondrá una escritura que se figurativiza mediante una palabra sofocada, ahogada pero viva. En su libro Paroles suffoquées, escribe: "Y sin embargo hay que hablar, a riesgo de sofocar, de ahogarse". Es característica de la filosofía de Kofman esta imbricación de la afirmación y de su imposibilidad de constituirse en afirmación 
"a riesgo de sofocar", escribe, como lo muestra en sus libros sobre la noción de denegación en Freud y la problematización del concepto de afirmación en el psicoanálisis. Aquí, la sofocación es la figura paradigmática de esta "palabra encogida, exigida y prohibida", es decir, de una enunciación simultáneamente requerida e imposible, que obliga a "tener que hablar sin poder hablar ni ser oído, tener que sofocar", escribe Kofman. En efecto, la palabra sofocada es aquella que ha "estado demasiado tiempo contenida, interrumpida, suspendida en la garganta y que os ahoga, os hace perder la respiración, os asfixia, os quita incluso cualquier posibilidad de empezar. Tener que hablar sin poder hablar ni ser oído, tener que sofocar" (Kofman, Paroles suffoquées, 31).

La expresión kofmaniana se concentra, así pues, no en el fin o en la simple imposibilidad de la palabra en el relato, sino en una palabra autobiográfica que se expresa mediante la retención, el encogimiento y la suspensión de la palabra literaria; una palabra retenida, ahogada, que espera ser dicha, y que parece vivir menos el final del decir que un futuro de lo decible arraigado en el crudo pasado del exterminio. Romper la especulación y la inteligibilidad del relato no conlleva aquí una escritura del desastre como en Blanchot sino una palabra suspendida, que Kofman estudia a partir de la figura de la aporía, a medio camino entre las lágrimas de la tragedia, por un lado, y, por el otro, la ironía, la experiencia de la risa, el chiste o el humor, en los libros donde la autora analiza el chiste freudiano y su relación con la afirmación y la denegación del inconsciente. ${ }^{4}$

Como recuerda Derrida en el texto que escribió tras la muerte de Kofman, la filósofa "reía mucho incluso cuando no reía e incluso, tantas veces, yo soy testigo como tantos otros, cuando no reía en absoluto" (Derrida, Cada vez único el fin del mundo,

${ }^{4}$ Cfr. Kofman, Comment se'n sortir y Pourquoi rit-on? Freud et le mot d'esprit. 
215). La risa de Kofman es para Derrida una compleja afirmación de la vida indisociable del gesto aporético que la autora despliega en sus lecturas de Freud donde la risa es una forma de subversión y de distancia en relación con el desastre. Por ello, la palabra sofocada de Kofman parece estar más cercana del pensamiento derridiano de la aporía y de la suspensión de conceptos incompatibles — risa y tragedia, duelo y afirmación - que de la ausencia de relato de Blanchot que ella misma, sin embargo, inscribe constantemente como el horizonte de sus textos autobiográficos. Como escribe Derrida en su preámbulo a su libro Aporías, si él recorre la aporía no es "para significar la parálisis o el impasse sino aquello mismo que hay que soportar para que una decisión, la responsabilidad, un acontecimiento o la hospitalidad, el don, sean posibles". Ciertamente, la aporía ni paraliza ni imposibilita la palabra de Kofman, puesto que la sofocación nace de una palabra propiamente contradictoria, inconjugable e imposible — a la vez exigida y prohibida-. Es aquí donde la aporía parece poder responder a la ausencia blanchotiana del relato, en la medida en que formula nuevamente, con otra figura, la dificultad enunciativa hija del fin de la palabra especulativa.

Sin embargo, más allá de la crítica de la inteligibilidad y de la especulación que tanto Blanchot como Kofman y Derrida comparten en distintos marcos teóricos, no podemos dejar de preguntarnos en qué se convierte la herencia blanchotiana del fin del relato especulativo y comunitario en el pensamiento de la deconstrucción derridiana y si dicha herencia se limita al gesto aporético o a la palabra sofocada. Para decirlo de otro modo, parece inevitable interrogar la transformación del fin del relato en Blanchot en la lectura derridiana de La locura de la luz, más allá de la praxis de la aporía kofmaniana, donde Derrida propone no una ausencia de relato sino una ampliación inaudita y sin límites de la noción de textualidad. La pregunta sería entonces cómo pensar la escritura blanchotiana del desastre que 
firma la muerte del relato literario, a partir de la ampliación de la noción de texto en Derrida. ¿Querría decir esto que Derrida no comparte la ausencia de relato blanchotiano al proponer el concepto de archi-escritura que, como sabemos, supone una textualidad generalizada y una ausencia de lo que él ha llamado el "afuera del texto"? ¿Debemos pensar como contradictorias la ausencia del relato y la archi-escritura, el fin del relato en Blanchot y la generalización de la noción de texto, de textualidad, en el pensamiento de Derrida?

En su libro titulado Parages, Derrida resigue la imposibilidad de fijar genéricamente los textos de Maurice Blanchot, que a veces llevan en el título o en los subtítulos la indicación de "ficción", a veces de "relato" y también de "novela", menciones que, señala Derrida, suelen desaparecer o transformarse de una edición a otra por decisión del autor. Asimismo, Derrida subraya desde las primeras páginas que "las voces que se enredan en este libro no traen con ellas un discurso, un único discurso que sea en última instancia de naturaleza teórica". Hay ahí distintos discursos, ninguno de ellos propone conclusiones en forma de teoremas, ya sea que éstos pertenezcan a la crítica literaria, a la poética, a la narratología, a la retórica, a la linguística, a la semántica. Y a fin de cuentas, esencialmente, el problema de este libro no sería ni hermenéutico ni filosófico. Ni los teoremas ni las tesis, ni los problemas narratológicos ni filosóficos blanchotianos interesan aquí a Derrida, que se concentra en una nueva figura de relato puesta en escritura a lo largo de La locura de la luz, donde la imposibilidad del relato se convierte en la forma que toma el propio relato. Por ello, y cito a Derrida, “el 'relato' no es simplemente un modo [en el sentido que Gérard Genette da a este término], ni un modo practicado o puesto a prueba como imposible; es también el nombre de un tema, el contenido temático pero no tematizable de algo de una forma textual" (Derrida, Parages, 261).

Sin embargo, llegados a este punto, podemos preguntarnos en qué se diferencia esta lectura derridiana de la definición que 
ya hemos avanzado del relato propiamente en la obra de Blanchot. O dicho de otro modo, ¿cómo queda transformado el fin del relato blanchotiano en la generalización derridiana de la noción de escritura a un conjunto de ámbitos que serían, en principio, extranjeros a la noción de escritura? Sabemos que la archi-escritura derridiana propone pensar como escritura no solamente el texto, literario o no, sino también todo aquello que tradicionalmente se ha venido oponiendo a la escritura, a saber, la oralidad, la voz o la palabra oral, así como toda manifestación gestual, corporal o artística aparentemente extranjera a la escritura. Para Derrida, la archi-escritura recubre todo horizonte de sentido, es por ello que en el marco de su lectura del relato en Blanchot, el filósofo de la deconstrucción postulará no solamente "la posibilidad del devenir-literatura de todo texto" (263), sino, de igual modo, una figura del relato que pone en escena su propia imposibilidad no como imposibilidad del modelo de la escritura sino como afirmación de ésta.

Lejos de conllevar una puesta en cuestión de la escritura, para Derrida la problemática del fin de la palabra enunciativa, especulativa e inteligible en el seno del relato de Blanchot, o las aporías de la palabra en Kofman, afirma "la ley del desbordamiento" (262) que caracteriza propiamente y en sentido fuerte la escritura. Esa escritura del después de la especulación que Blanchot piensa como el fin de una palabra hilvanada y Kofman como una palabra suspendida en su sofoco, se convierte en ese texto ilimitado y generalizado que Derrida llama archi-escritura, quizás para mostrar con dicho desplazamiento que la escritura ya siempre habrá sido el lugar donde la palabra cortada y el silencio buscan sin encontrar su propio género, una forma literaria o una figura. La archi-escritura derridiana o escritura originaria recubriría, entonces, no solamente el relato sino su fin, su ausencia, su desastre, en Blanchot; no solamente la palabra, sino su sofoco, su interrupción, su suspensión, en Kofman. 
Para concluir con la ampliación del modelo escritural, Derrida daría razón a la diferencia blanchotiana entre tesis teórica y tesis literaria con la que abríamos este ensayo, puesto que la hipótesis de la concepción derridiana de la archi-escritura postula, ante todo, la indisociabilidad del pensar y del escribir, de la filosofía y de su texto. La archi-escritura derridiana sería en este sentido una especie de "tesis literaria" que no es nada "sin" el texto en la que se escribe.

\section{REFERENCIAS}

Antelme, Robert, La especie humana [1947], trad. Trinidad Richelet, Madrid, Arena, 2001.

Blanchot, Maurice, La parte del fuego [1949], trad. Isidro Herrera, Madrid, Arena, 2007.

— La locura de la luz [1973], trad. Alberto Ruiz de Samaniego, Madrid, Tecnos, 2001.

—, La conversación infinita [1969], trad. Isidro Herrera, Madrid, Arena, 2008.

—_, "L'idylle", en Après coup. Précédé par Le ressassement éternel, París, Minuit, 1983.

__ El espacio literario [1991], trad. Vicky Palant y Jorge Jinkins, Barcelona, Paidós, 1992.

DerRIDA, Jacques, Mémoires d'aveugle. L'autoportrait et autres ruines, París, Réunion des Musées Nationaux, 1990.

—, Aporías [1996], trad. Cristina de Peretti, Barcelona, Paidós, 1998.

_, Parages, París, Galilée, 1996.

—, Cada vez único el fin del mundo [2003], trad. Manuel Lázaro Arranz, Madrid, Pre-Textos, 2005.

Kofman, Sarah, Cámara oscura. De la ideología [1973], trad. Anne Leroux, Madrid, Taller J. B., 1975.

—, Pourquoi rit-on? Freud et le mot d'esprit, París, Galilée, 1986.

_, Paroles suffoquées, París, Galilée, 1987.

— , "La mort conjurée. Remarques sur la Leçon d'anatomie du Docteur Tulp", en La Part de l'Oeil, 11, 1995, 71-75. 